\title{
Peningkatan Sifat Mekanis Al-Mg-Si dengan Proses Aging untuk Aplikasi Selongsong Peluru
}

\author{
Dwita Suastiyanti $^{1, \mathrm{a})}$, Bambang Agus Topan ${ }^{2, \mathrm{~b})}$, Marlin Wijaya ${ }^{3, \mathrm{c})}$ \\ ${ }^{1,2)}$ Program Studi Teknik Mesin ITI, \\ Jl. Raya Puspiptek Serpong, Tangerang Selatan-Banten, Indonesia, 15320 \\ ${ }^{2)}$ Badan Pengkajian dan Penerapan Teknologi (BPPT)-Puspiptek , \\ J1. Raya Puspiptek Serpong, Tangerang Selatan-Banten, Indonesia, 15320 \\ a)dwita_suastiyanti@iti.ac.id, ${ }^{\text {b) }}$ bambangtopan32@gmail.com, ${ }^{c}$ marlin.wijaya@bppt.go.id
}

\begin{abstract}
Abstrak
Aluminium paduan Al-Mg-Si khususnya T6061 merupakan paduan yang pada umumnya diaplikasikan untuk otomotif dan alat-alat konstruksi. Penelitian ini diarahkan untuk peningkatan sifat mekanis khususnya kekerasan material T6061 untuk diaplikasikan sebagai selongsong peluru. Selama ini material untuk selongsong peluru banyak menggunakan kuningan yang mempunyai density yang lebih besar daripada aluminium padahal sebagai selongsong peluru diperlukan material yang ringan tetapi kuat sehingga dapat menembakan peluru dengan lancar dan mudah. Untuk peningkatan sifat mekanis dilakukan perlakuan panas precipitation hardening melalui proses pemanasan pada temperatur $500^{\circ} \mathrm{C}$ selama 1 jam kemudian dicelup di dalam air sampai mencapai temperatur kamar, setelah itu untuk peningkatan kekerasan dilakukan proses aging (penuaan) pada temperatur 90, 120, 150, 180 dan $210^{\circ} \mathrm{C}$ masing-masing selama 8,9 dan 10 jam. Karakterisasi aluminium setelah mengalami precipitation hardening adalah dengan melakukan pengujian kekerasan metode Vickers dan pengamatan struktur mikro. Dari hasil pengujian kekerasan diperoleh hasil bahwa kekerasan terus meningkat mulai dari temperatur aging $90^{\circ} \mathrm{C}$ sampai dengan temperatur aging $150^{\circ} \mathrm{C}$. Kekerasan maksimum diperoleh pada temperatur aging $150^{\circ} \mathrm{C}$ sebesar $103 \mathrm{HV}$. Di atas temperatur $150^{\circ} \mathrm{C}$ terjadi penurunan kekerasan yang menandakan bahwa terjadi over aging pada temperatur di atas $150^{\circ} \mathrm{C}$ yang ditandai dengan makin membesarnya presipitat $\mathrm{Mg}_{2} \mathrm{Si}$. Kondisi aging optimum yang dapat diterapkan untuk precipitation hardening T6061 yang diaplikasikan untuk selongsong peluru adalah temperatur aging $150^{\circ} \mathrm{C}$ selama 8,9 dan 10 jam karena mempunyai nilai kekerasan sesuai dengan spesifikasi yang diharapkan.
\end{abstract}

Kata kunci: T6061, precipitation hardening, aging

\begin{abstract}
Al-Mg-Si aluminum alloy especially $\mathrm{T6061}$ is an alloy which is generally applied to automotive and construction equipment. This research is aimed at improving the mechanical properties, especially the hardness of the T6061 material to be applied as a bullet cartridge. So far, the material for bullet casings uses a lot of brass which has a greater density than aluminum whereas as bullet casings a light weight but strong material is needed so that it can fire bullets smoothly and easily. To improve the mechanical properties of precipitation hardening heat treatment is carried out through a heating process at a temperature of $500^{\circ} \mathrm{C}$ for 1 hour then dipped in water until it reaches room temperature, after that to increase the hardness the aging process is carried out at temperatures of 90, 120, 150, 180 and $210^{\circ} \mathrm{C}$ for 8.9 and 10 hours respectively. The characterization of aluminum after hardening precipitation is by testing the hardness of the Vickers method and observing the microstructure. From the results of the hardness test, it was found that the hardness continued to increase from the aging temperature of $90^{\circ} \mathrm{C}$ to the temperature of aging $150^{\circ} \mathrm{C}$. The maximum hardness is obtained at aging temperature of $150^{\circ} \mathrm{C}$ of $103 \mathrm{HV}$. Above the temperature of $150^{\circ} \mathrm{C}$ there is a decrease in the hardness which indicates that there is over aging at temperatures above $150^{\circ} \mathrm{C}$ which is characterized by the enlargement of the $\mathrm{Mg}_{2}$ Si precipitate. The optimum aging condition that can be applied to precipitation hardening T6061 that is applied to cartridge casings is the aging temperature of $150^{\circ} \mathrm{C}$ for 8,9 and 10 hours due to having hardness for bullet cartridge
\end{abstract}

Keywords: T6061, precipitation hardening, aging 


\section{PENDAHULUAN}

Kemajuan teknologi sekarang ini telah menghasilkan berbagai kreasi dalam segala hal, yang bertujuan untuk memudahkan segala aktifitas manusia. Ada berbagai macam senjata militer yang tersedia, mulai dari senjata api laras pendek, hingga senjata api laras panjang. Komponen dari senjata api yang banyak diproduksi masal di Indonesia umumnya adalah peluru senjata api. Peluru senjata api diproduksi agar memudahkan pasokan persenjataan militer, maka diharapkan peluru senjata api didesain secara efektif dan efisien serta menggunakan material komponen berkualitas.

Pada proses peledakan yang terjadi di dalam selongsong peluru, tenaga yang dihasilkan oleh bubuk mesiu saat peledakan sangatlah tinggi. Jika selongsong tidak mampu menahan daya ledak dari proses pembakaran tersebut, dapat dipastikan selongsong dapat pecah. Agar tidak terjadi kejadian tersebut maka diharuskan mengetahui kekuatan dari selongsong tersebut dan diperlukan material yang kuat dan ringan. Selongsong juga dimaksimalkan untuk mampu menahan gaya dari pelatuk senapan dan hasil pembakaran bubuk mesiu. Dengan adanya gaya tersebut selongsong harus mampu menerima beban tersebut.

Umumnya selongsong peluru terbuat dari logam paduan kuningan cartridge brass, yaitu logam paduan antara unsur tembaga dan seng dengan komposisi $70 \%$ tembaga dan $30 \%$ seng yang mengalami pengerolan[1]. Akan tetapi kuningan merupakan material yang berat dan tidak mempunyai kekuatan yang memadai untuk menahan daya ledak peluru.

Dari penelitian Widyantoro dan E. Kurniawan (2018) yang melakukan penelitian tentang tentang pengaruh temperatur aging terhadap paduan aluminium seri 6061 terhadap nilai kekerasan dan kekuatan impact, ternyata proses aging dapat meningkatkan nilai kekerasan, dimana peningkatan maksimum pada temperatur $185^{\circ} \mathrm{C}$.Proses aging juga dapat meningkatkan kekuatan impact pada temperatur $175^{\circ} \mathrm{C}$. Temperatur $175^{\circ} \mathrm{C}$ merupakan temperatur optimum untuk meningkatkan kekuatan impact, bila melebihi temperatur tersebut akan mengalami penurunan kekuatan impact pada temperatur $185^{\circ} \mathrm{C}[2]$.

Dari penelitian Hendri Sukma (2018) yang melakukan penelitian tentang pengaruh penuaan terhadap peningkatan kekerasan material komposit aluminium, ternyata terjadi peningkatan nilai kekerasan dengan semangkin tingginya temperatur dan lamanya waktu aging, nilai kekerasan pada temperatur aging $200^{\circ} \mathrm{C}$ lebih rendah dari pada nilai kekerasan pada temperatur aging $180^{\circ} \mathrm{C}$ dan relatif sama dengan kekerasan pada temperatur aging $140^{\circ} \mathrm{C}[3]$.

Pada penelitian ini, dicoba menggunakan material pengganti kuningan untuk selongsong peluru yaitu aluminium paduan $\mathrm{Al}-\mathrm{Mg}-\mathrm{Si}$ tipe T6061. Untuk peningkatan sifat mekanis T6061 dilakukan dengan proses perlakuan panas precipitation hardening yang diawali dengan pemanasan (solution treatment) pada $500^{\circ} \mathrm{C}$ selama 1 jam, kemudian dicelup ke dalam media air. Peningkatan kekerasan diperoleh melalui proses aging setelah pencelupan, yaitu pada temperatur 90,120, 150 dan 180 dan $210^{\circ} \mathrm{C}$ masing-masing selama 8,9 dan 10 jam. Dari parameter-parameter yang digunakan tersebut akan ditentukan kondisi yang paling optimum untuk pencapaian kekerasan T6061 yang sesuai dengan standar kebutuhan selongsong peluru.

\section{LANDASAN TEORI}

\section{A.Material Aluminium Paduan Al-Mg-Si}

Aluminium paduan merupakan aluminium yang ditambah dengan elemen paduan. Elemen paduan yang biasa digunakan seperti tembaga, magnesium, silikon, seng, bismuth, timbal, boron, nikel, titanium, chromium, vanadium, dan zirconium. Tujuan dari penambahan elemen paduan salah satunya adalah untuk meningkatkan sifat mekanis aluminium. Paduan aluminium dikelompokkan menjadi dua kelompok utama yaitu kelompok produk casting dan produk forging (wrought). Jenis aluminium paduan saat ini sangat banyak dan tidak menutup kemungkinan ditemukannya lagi jenis aluminium paduan baru, oleh karena itu dibuatlah sistem penamaan sesuai dengan komposisi dan karakteristik aluminium paduan tersebut untuk memudahkan pengklasifikasiannya.Aluminium paduan diklasifikasikan dalam berbagai standar oleh berbagai negara di dunia. Standard Aluminium Association (AA) di Amerika mengunakan penandaan dengan empat angka.

Paduan Al-Mg-Si mempunyai kekuatan yang kurang baik sebagai bahan tempa dibandingkan dengan paduanpaduan lainya. Tetapi sangat liat, sangat baik mampu bentuknya untuk penempaan, ekstrusi dan lain-lain. Salah satu paduan seri 6000 adalah 6061 yang banyak digunakan untuk rangka konstruksi, otomotif dan sekarang banyak diarahkan untuk keperluan ketahanan militer[4,5,6]. Seri 6000 magnesium dan silikon sebagai elemen paduan utama mempunyai sifat antara lain kekuatan sedang, ketahanan korosi yang baik, kemampuan las yang baik, dan kinerja proses yang baik (pembentukan ekstrusi yang mudah).

\section{B.Selongsong Peluru}

Selongsong peluru atau patrun adalah benda yang merupakan wadah yang membungkus proyektil peluru dan terdiri dari propelan (biasanya bubuk mesiu), rim, dan primer. Bubuk mesiu berfungsi sebagai pencetus ledakan yang mendorong proyektil peluru dengan energi kinetik. Selongsong peluru secara kedap udara mengunci ruang pembakaran amunisi dari segala arah kecuali pada bagian bawah selongsong. Setelah pelatuk senapan ditarik, pin pemicu tembakan akan memukul primer (Gambar 1) dan memicu percikan api yang terjadi akibat pukulan pin, primer akan membakar gas pada bubuk mesiu. Gas yang terbakar dari bubuk mesiu mendorong proyektil peluru lepas dari selongsong-nya. Setelah peluru terlepas, tekanan pada selongsong akan hilang dan menjadikan selongsong tersebut terlontar keluar dari ruang pembakaran. Persyaratan standar yang ditetapkan 
perusahaan untuk sifat mekanis selongsong peluru mengacu pada standar NATO SS109, yaitu 80-95 Hardness Vickers[7]

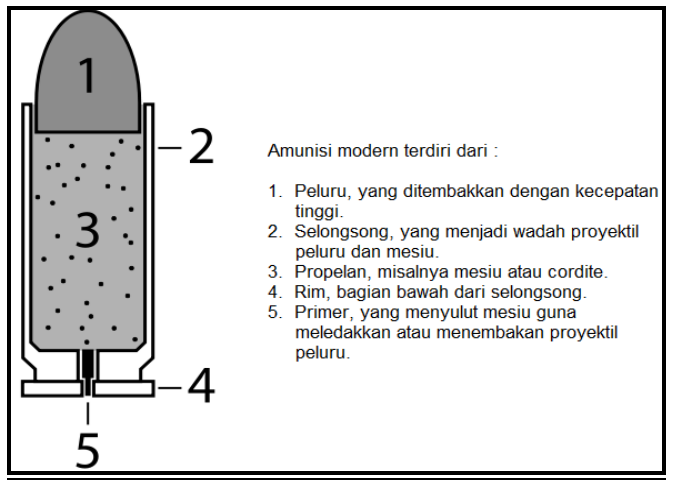

Gambar 1. Struktur dari Amunisi Peluru

Bahan selongsong (Gambar 2) terbuat dari lembaran kuningan atau tembaga yg di-"punch" (ditekan) dengan menggunakan alat punch. Selongsong peluru adalah benda yang merupakan wadah yang membungkus proyektil atau anak peluru dan terdiri dari propelan (biasanya bubuk mesiu), rim, dan primer. Bubuk mesiu berfungsi sebagai pencetus ledakan yang mendorong proyektil peluru dengan energi kinetik. Selongsong peluru baru di kenal pada penggunaan amunisi senjata api modern. Senapan api jenis awal seperti senapan kopak, senapan lontak atau pemuras belum mengenal penggunaan "selongsong" pada sebuah peluru.

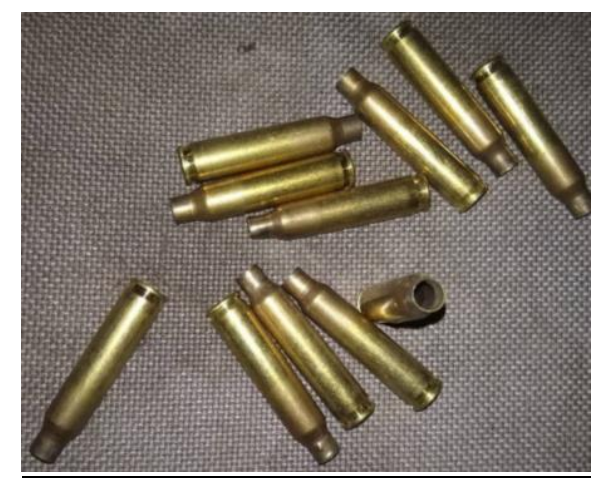

Gambar 2. Selongsong Peluru

\section{C.Perlakuan Panas Aluminium Paduan}

Perlakuan panas pada aluminium paduan dikenal dengan nama precipitatin hardening yang dimulai dengan proses pemanasan (solution treatment) kemudian diikuti dengan proses pencelupan dalam media pendingin (air). Setelah itu dilakukan proses aging (penuaan) untuk peningkatan kekerasan aluminium paduan. Tidak semua aluminium paduan dapat dilakukan perlakuan panas untuk peningkatan kekerasan/kekuatannya. Aluminium paduan yang dapat dilakukan proses perlakuan panas adalah aluminium paduan seri $2 \mathrm{xxx}, 6 \mathrm{xxx}$ dan $7 \mathrm{xxx}$. Tahapan proses perlakuan panas aluminium paduan ditunjukkan pada Gambar 3.

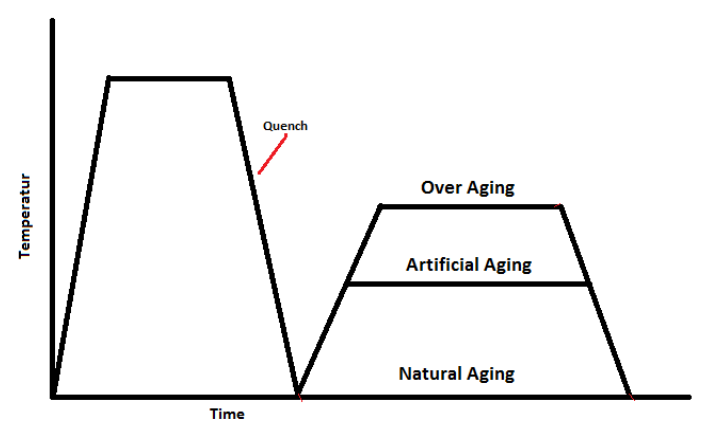

Gambar 3. Tahapan Proses Precipitation Hardening

Kondisi over aging terjadi jika panas yang diberikan pada saat aging berlebihan atau waktu aging terlalu lama. Akibat dari kondisi ini adalah terjadi penurunan kekerasan kembali yang diakibatkan endapan $\mathrm{Mg}_{2} \mathrm{Si}$ yang semula halus dan tersebar merata menjadi tumbuh membesar dan terlokalisir pada tempat tertentu saja.

\section{METODE PENELITIAN}

Penelitian dimulai dengan persiapan material dan peralatan laboratorium yang diperlukan (furnace/dapur pemanas, gergaji potong, coolant, stopwatch) yang diikuti dengan tahap-tahap selanjutnya mengacu pada diagram alir seperti ditunjukkan pada Gambar 4. Proses perlakuan panas dilakukan di Laboratorium Rekayasa Material - Institut Teknologi Indonesia dan pengujian karakterisasi sampel dilakukan di B2TKS - Puspiptek Serpong. Material uji T6061 mempunyai komposisi kimia seperti ditunjukkan pada Tabel 1.

Tabel 1. Komposisi Kimia Unsur Paduan T6061

\begin{tabular}{ccccccccc}
\hline $\mathrm{Mg}$ & $\mathrm{Si}$ & $\mathrm{Cu}$ & $\mathrm{Cr}$ & $\mathrm{Fe}$ & $\mathrm{Mn}$ & $\mathrm{Zn}$ & $\mathrm{Ti}$ & Lain2 \\
\hline $0,8-$ & $0.4-$ & $0,15-$ & $0,04-$ & 0,7 & 0,15 & 0,25 & 0,15 & $<0,15$ \\
1,2 & 0,8 & 0,4 & 0,35 & & & & & \\
\hline
\end{tabular}

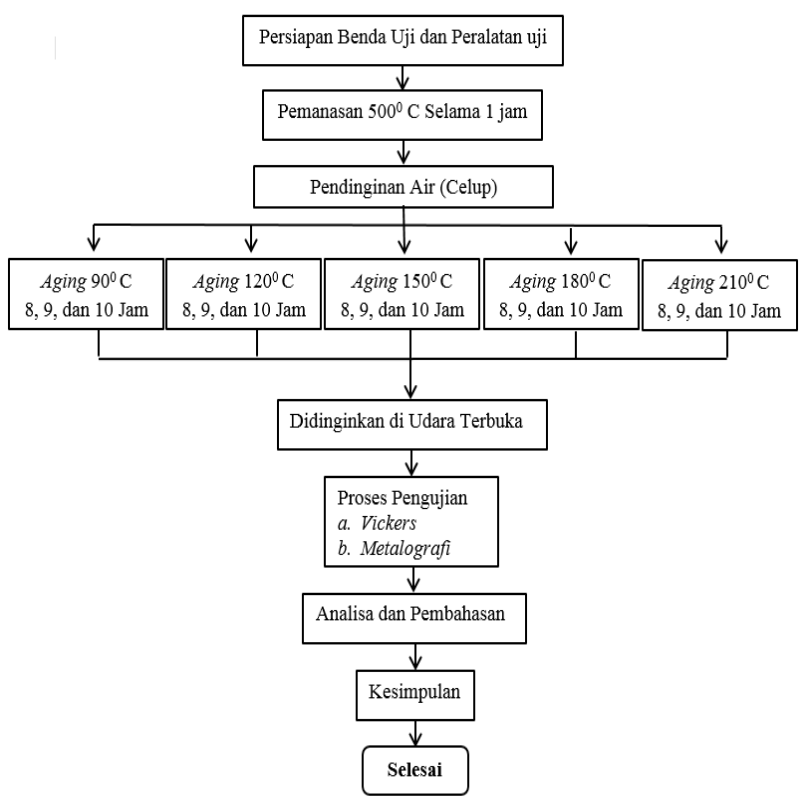

Gambar 4. Diagram Alir Penelitian 
Proses pemanasan dilakukan pada temperatur $500^{\circ} \mathrm{C}$ selama 1 jam dimana pada kondisi temperatur tersebut material berada pada fasa tunggal $\alpha$. Proses aging dilakukan pada variasi temperatur 90,120,150,180 dan $210^{\circ} \mathrm{C}$ masing-masing selama 8,9 dan 10 jam. Karakterisasi dilakukan melalui pengujian kekerasan metode Vickers dan pengamatan metalografi untuk mengetahui morfologi dan ukuran presipitat $\mathrm{Mg}_{2} \mathrm{Si}$ yang terbentuk.

\section{HASIL DAN PEMBAHASAN \\ A.Hasil Uji Kekerasan}

Dari hasil uji kekerasan dengan metode Vickers diperoleh hasil seperti ditunjukkan pada Tabel 2.

Tabel 2. Hasil Uji Kekerasan untuk Semua Parameter Aging

\begin{tabular}{|c|c|c|c|c|c|c|c|}
\hline \multirow{2}{*}{ No } & \multirow{2}{*}{$\begin{array}{l}\text { Waktu } \\
\text { (jam) }\end{array}$} & \multirow{2}{*}{ titik } & \multicolumn{5}{|c|}{ Temperatur $\left({ }^{\circ} \mathrm{C}\right)$} \\
\hline & & & 90 & 120 & 150 & 180 & 210 \\
\hline \multicolumn{3}{|c|}{ Nilai kekerasan awal } & \multicolumn{5}{|c|}{50} \\
\hline & & 1 & 66 & 71 & 106 & 80 & 75 \\
\hline \multirow[t]{4}{*}{1} & 8 & 2 & 65 & 71 & 102 & 78 & 75 \\
\hline & & 3 & 63 & 70 & 100 & 82 & 72 \\
\hline & Rata-r: & & 65 & 71 & 103 & 80 & 74 \\
\hline & & 1 & 66 & 69 & 99 & 84 & 72 \\
\hline \multirow[t]{4}{*}{2} & 9 & 2 & 66 & 69 & 102 & 80 & 72 \\
\hline & & 3 & 66 & 69 & 100 & 82 & 70 \\
\hline & Rata-r: & & 66 & 69 & 100 & 82 & 71 \\
\hline & & 1 & 67 & 68 & 99 & 82 & 72 \\
\hline \multirow[t]{3}{*}{3} & 10 & 2 & 66 & 96 & 97 & 82 & 74 \\
\hline & & 3 & 66 & 69 & 96 & 80 & 72 \\
\hline & Rata-r: & & 66 & 67 & 97 & 81 & 73 \\
\hline
\end{tabular}

Tabel 2 menujukkan bahwa makin lama waktu aging untuk temperatur aging yang sama tidak menunjukkan keteraturan naik dan turunnya nilai kekerasan, akan tetapi perubahan yang siginifikan terjadi jika dilihat dari perubahan temperatur aging. Pada temperatur aging mulai dari $90^{\circ} \mathrm{C}$ sampai dengan $150^{\circ} \mathrm{C}$ terlihat adanya peningkatan kekerasan yang signifikan yaitu 65-103 HV untuk waktu aging 8 jam, nilai kekerasan 55-100 HV untuk waktu aging 9 jam dan nilai kekerasan 66-97 HV untuk waktu aging 10 jam. Akan tetapi jika temperatur aging dinaikkan menjadi $180^{\circ} \mathrm{C}$ akan terjadi penurunan kekerasan dari yang sebelumnya demikian pula jika temperatur aging dinaikkan kembali menjadi $210^{\circ} \mathrm{C}$ terjadi penurunan kekerasan dari kekerasan yang diperoleh pada temperatur aging $180^{\circ} \mathrm{C}$. Fenomena ini yang disebut dengan over aging dimana terjadi kelebihan panas akibat temperatur aging yang terlalu tinggi. Nilai kekerasan yang dicapai pada setiap temperatur aging berkaitan erat dengan morfologi presipitat $\mathrm{Mg}_{2} \mathrm{Si}$ yang terbentuk dan akan dibahas pada hasil pengamatan metalografi. Data-data pada Tabel 1 yang menunjukkan naik turunnya nilai kekerasan dapat diilustrasikan pula dengan grafik seperti ditunjukkan pada Gambar 5, 6 dan 7.

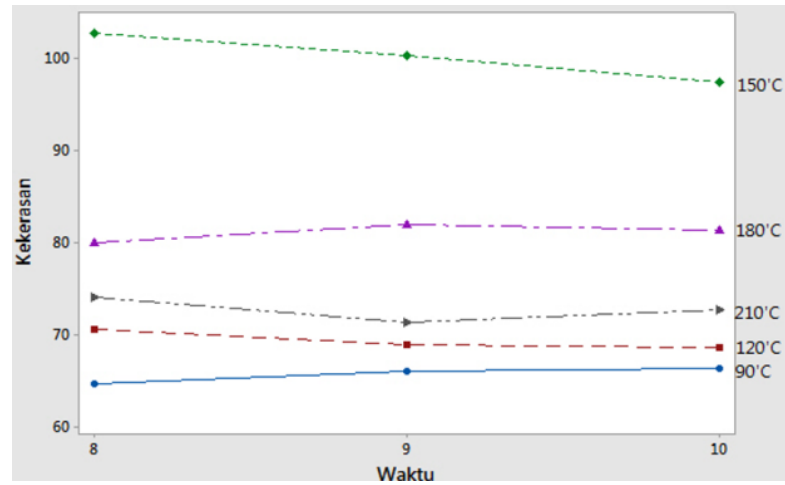

Gambar 5. Pengaruh Waktu Aging Terhadap Kekerasan Pada Temperatur Aging Yang Berbeda

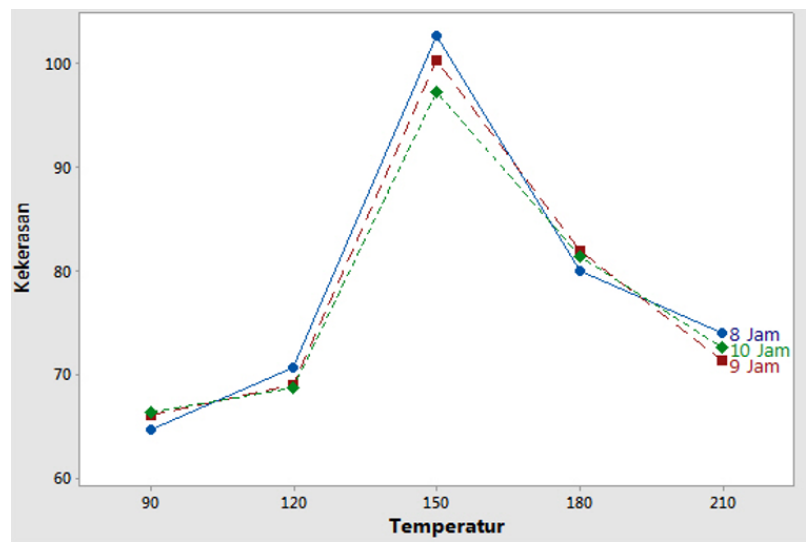

Gambar 6. Pengaruh Temperatur Aging Terhadap Kekerasan Pada Waktu Aging Yang Berbeda

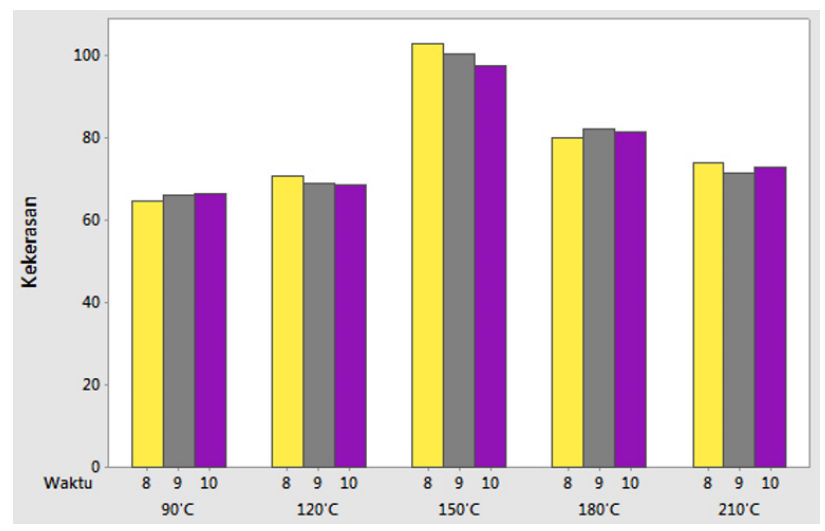

Gambar 7. Pengaruh Temperatur dan Waktu Aging Terhadap Kekerasan

Secara garis besar, Gambar 5,6 dan 7 menunjukkan bahwa kondisi over aging terjadi pada temperatur di atas $150^{\circ} \mathrm{C}$ dan kekerasan maksimum diperoleh pada temperatur $150^{\circ} \mathrm{C}$ yaitu $103 \mathrm{HV}$ untuk waktu aging 8 jam, $100 \mathrm{HV}$ untuk waktu aging 9 jam dan $97 \mathrm{HV}$ untuk waktu aging 10 jam.

\section{B.Pengamatan Metalografi}

Dari hasil pengamatan metalografi diperoleh bentuk morfologi presipitat $\mathrm{Mg}_{2} \mathrm{Si}$ untuk kondisi sebelum dan 
sesudah terjadi over aging seperti ditunjukkan pada Gambar 8,9,10 dan 11(diambil contoh beberapa gambar yang perubahan kekerasannya siginifikan)

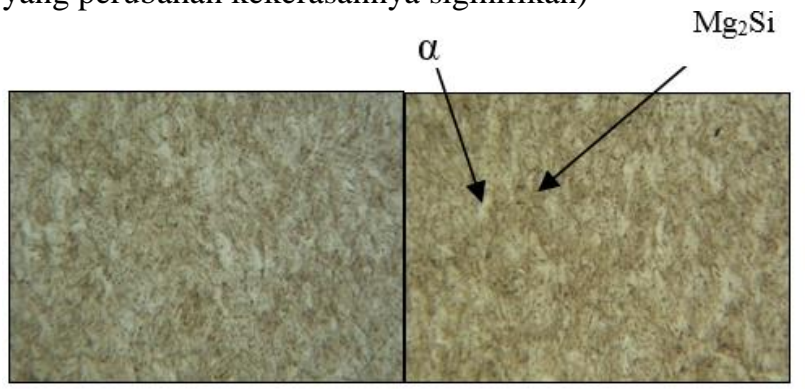

Gambar 8. Presipitat $\mathrm{Mg}_{2} \mathrm{Si}$ (daerah gelap) dan $\alpha$ (daerah terang) Pada Temperatur Aging $90^{\circ} \mathrm{C}$ dan Waktu Aging 8, 9 Jam (Kekerasan Terendah)

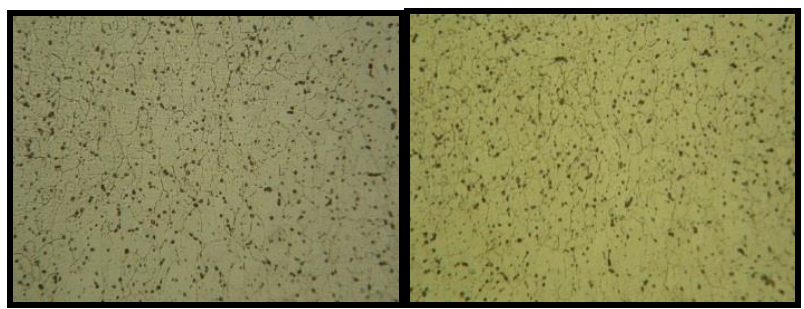

Gambar 9. Presipitat $\mathrm{Mg}_{2} \mathrm{Si}$ dan $\alpha$ (daerah terang) Pada Temperatur Aging $150^{\circ} \mathrm{C}$ dan Waktu Aging 8, 9 Jam (Kekerasan Tertinggi)

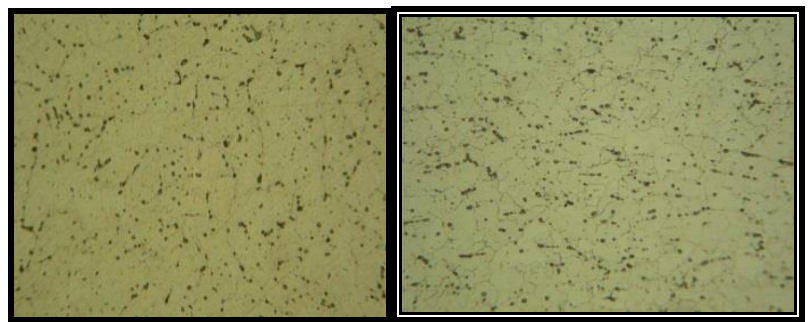

Gambar 10. Presipitat $\mathrm{Mg}_{2} \mathrm{Si}$ dan $\alpha$ (daerah terang) Pada Temperatur Aging $180^{\circ} \mathrm{C}$ dan Waktu Aging 8, 9 Jam (Kondisi over aging)

Kekerasan pada temperatur awal aging $90^{\circ} \mathrm{C}$ menunjukkan nilai yang paling rendah disebabkan karena pada kondisi tersebut diperoleh presipitat $\mathrm{Mg}_{2} \mathrm{Si}$ yang masih kasar (Gambar 8). Ketika temperatur aging dinaikkan menjadi $150^{\circ} \mathrm{C}$ terjadi perubahan ukuran presipitat yang signifikan dimana ukuran presipitat menjadi sangat halus dan terdistribusi merata (Gambar 9). Pada kondisi ini diperoleh nilai kekerasan yang paling tinggi. Akan tetapi jika temperatur aging ditingkatkan lagi menjadi $180^{\circ} \mathrm{C}$ terjadi perubahan ukuran presipitat yaitu lebih besar daripada yang diperoleh pada temperatur aging $150^{\circ} \mathrm{C}$ (Gambar 10). Pada kondisi ini nilai kekerasan menurun dari sebelumnya (temperatur aging $150^{\circ} \mathrm{C}$ ). Fenomena ini yang disebut dengan kondisi over aging.

\section{KESIMPULAN}

Dari hasil penelitian ini dapat diambil beberapa kesimpulan sebagai berikut :

1. Nilai kekerasan maksimum dicapai pada temperatur aging $150^{\circ} \mathrm{C}$ dan waktu aging 8 jam yaitu sebesar $103 \mathrm{HV}$.

2. Terjadi kondisi over aging pada temperatur aging di atas $150^{\circ} \mathrm{C}$

3. Pada kondisi nilai kekerasan maksimum, diperoleh ukuran presipitat $\mathrm{Mg}_{2} \mathrm{Si}$ yang paling halus

4. Pada kondisi over aging, presipitat $\mathrm{Mg}_{2} \mathrm{Si}$ tumbuh membesar dan lebih besar daripada temperatur aging sebelumnya.

5. Parameter yang direkomendasikan untuk diterapkan pada perlakukan panas precipitation hardening aluminium T6061 adalah temperatur aging $150^{\circ} \mathrm{C}$ selama 8,9 dan 10 jam karena pada kondisi tersebut diperoleh nilai kekerasan yang mendekati nilai kekerasan standar (80-95 HV).

\section{UCAPAN TERIMA KASIH}

Ucapan terima kasih disampaikan kepada Badan Pengkajian dan Penerapan Teknologi - Puspiptek Serpong yang telah memberikan dukungan finansial baik dalam bentuk penyediaan sampel maupun pengujian/karakterisasi sampel.

\section{REFERENSI}

[1] I. Basori, B. Sofyan, Initial observation on the characteristics of small caliber cartridge case before and after firing, Conference Paper Seminar Nasional Mesin dan Teknologi Kejuruan Universitas Negeri Jakarta, 2015.

[2] Widyantoro, E. Kurniawan, Pengaruh variasi temperatur aging terhadap aluminium 6061 terhadap uji impak, kekerasan dan struktur mikro, Diploma Thesis, Repository Institut Teknologi Sepuluh November, 2018

[3] H. Sukma, D. Rahmalina, E.A. Pane, A. Gantina, Pengaruh proses penuaan untuk meningkatkan kekerasan material komposit matriks aluminium, Flywheel Jurnal Teknik Mesin Untirta, Vol. 4, No. 1, 2018, 49-55

[4] L.A.N. Wibawa, , Disain dan analisis kekuatan rangka meja kerja (workbench) Balai Lapan Garut menggunakan metode elemen hingga, JTM-ITI (Jurnal Teknik Mesin ITI), Vol. 3, No. 1, 2019, 13-17

[5] A. Naafila, A. Purnowidodo, P.H. Setyarini, Pengaruh waktu solution treatment terhadap kekuatan tarik aluminium paduan AA 7075-T6, Prosiding Seniati, Vol. 5, No. 4, 2019, 215-220

[6] M.A. Qubro, A.M. Sakti, Analisis warna dan kekerasan dari pemberian kadar garam $(\mathrm{NaCl})$ pada proses pengecoran propeller dengan material aluminium (Al 6061), Jurnal Pendidikan Teknik Mesin, Vol. 6, No. 2, 2017, 44-50

[7] E. Febriyanti, A. Suhadi, D. Priadi, R. Riastuti, Analisis mampu bentuk bahan baku selongsong amunisi $\mathrm{Cu}-\mathrm{Zn}$ 70/30 setelah deformasi pada suhu $500^{\circ} \mathrm{C}$, Majalah Ilmiah Pengkajian Industri, 2015, Vol.9, No.3. 